\title{
The Correlation Between the Sciences of Law and Economics
}

It has been traditional and it is usual for analytical jurists to isolate the single element of positive physical force as the one indispensable constituent element of "law" and of "legal relations." A similar attitude with respect to economics has had effect in the isolation of the element of scarcity as the smgle essential constituent of the subject-matter of that science. Besides pointing this out, Professor Commons has thoroughly demonstrated ${ }^{2}$ that, as Schmoller contended in his debate with Menger on Methodology, this single element is altogether inadequate for

1 "Law . . . is that rule of action which is prescribed by some superior, and which the inferior is bound to obey." BLACKstone, Comanentarmes (3d ed. by Chase, 1893) 1. The following words of Sir Henry Maine are quoted in the footnote to the above: "The word 'law' has come down to us in close association with two notions, the notion of order and the notion of force. .."

"The matter of jurisprudence is positive law: law, simply and strictly socalled; or law set by political superiors to political inferiors. . . A law, in the most general and comprehensive acceptation in which the term, in its literal meaning, is employed, may be said to be a rule laid down for the guidance of an intelligent being having power over him." Brown, The AustinIaN Theory of Law (1906) 1:

"The law is the body of principles recognized and applied by the state in the administration of justice... The administration of justice may ... be defined as the inaintenance of right within a political community by ineans of the physical force of the state. The instrument of coercion employed by any regulative system is called a sanction, and any rule of right supported by such means is said to be sanctioned. Thus physical force, in the various methods of its application, is the sanction applied by the state in the administration of justice." SAIMrOND, JURISPRUDENCE (6th ed. 1920) 9-12.

"The central idea of law in a formal sense is force, power, domimion. This leading concept is carried down into all technical operations of the law. The corollary is the unilateral quality of all legal phenomena. All jural relations without exception exhibit this quality of unilateral power not only in their duration but also in their creation and ending." Kocourex, JURAL RELATIONS (1927) 13.

"Law is never applied by the state in any other way than by coercion ... Legal relations also are coercive. The coercion implicated in abstract form in legal rules gives to legal relations their practical jural validity." Ibid. 60-61.

2 Especially in the following works: Legar Foundations of Capitazism (1924); Reasonable Vatue (1925); Notes on Anatytic and Functional Econonics (1926); ANGLO-AMIERICAN LAw AND EcoNONHCS (1926); Law and Economics (1925) 34 Y YLE I. J. 371, the writer owes a very great debt, indeed, to Professor Commons for whatever of value is to be found in this discussion, which is a revised portion of certain work done under him by the writer, and is based wholly on his writings and to a very great extent, if not altogether, merely presents again in the writer's own words, ideas originally expressed or suggested by Professor Commons in his works. However, the unquoted statements lierein are those of the present writer and he takes the entire responsibility for them. It should be added that a number of the terms used herein are terms which have been adopted by Professor Commons and his usage is employed, as for example the terms, "complimentary factor," "limiting factor," "limits," "inducement," "sanction," "working rule," "futurity." 


\section{economics as an applied science, i.e. for the functional study of social phenomena with reference to scarcity.}

"Analytic economics has to do solely with the function of scarcity just as analytic jurisprudence has to do solely with the function of force. Its highest development has been that of the so-called psychological, especially the Austrian, economists. The 'economic man' of these analytic economists is an abstraction of scarcity, just as the jurisprudential man of the analytic jurists is an abstraction of force from the other social relations of man, that is from its functional relation to the other functions. . . The analytic economists of the classical school (Adam Smith, Riccardo) took scarcity for granted, and it was the hedonic school (Jevons, Menger) who analyzed and perfected its formula. They extracted, specialized, isolated and organized the scarcity relation of wants to resources, leading up to the procedure of a modern market, just as analytic jurists did for the violence relation of superior to inferior, leading up to the procedure of a modern court of law. It was the elaboration of this universal function of force that created the so-called exact science of economics, with its equilibrium of demand and supply, resulting in changes in price and the details of this equilibrium appeared as the theory of diminishing utility, increasing disutility, marginal utilty, complementary goods, rent surpluses, and so on. This field of inquiry is properly designated analytic economics, for its essential method consists in eliminating all other functions under the name of "friction," the inference being that friction was something extraneous to the pure science of economics and would be eliminated if all individuals were perfectly free, infinitely intelligent, and absolutely equal in person and property. In other words, the exact science of economics eliminated the "frictions" caused by differences in efficiency, sovereignty, custom and futurity, by assuming that these were not only constant, but also operated equally upon equal individuals, and then worked out the formula for scarcity, introducing at points the differential advantages occasioned by differences in efficiency of individuals." 3

"Menger ... sought, on the analogy of the physical sciences, to abstract from all other social phenomena the simplest typical trait and physical relation upon which an 'exact' science of economics should be constructed. His typical traits were self-interest and utility, and his typical relation was that existing between the quantity of useful goods needed by individuals and the quantity of such goods within the individuals control at the time and place. This typical relation gave him the distinction between economic goods and non-economic goods, a distinction which we may designate simply as the relation of Scarcity. Economics becomes the exact science of scarcity. Schnoller contends that this abstraction of self-interest gave us a shadowy phantom, an imaginary Robinson Crusoe, substituted for the complex historical, social, legal and economic traits and relations required to reveal the truths of political economy. He conceded the need of abstraction in order to ascertain the truth, but contended that many abstractions were needed, instead of one, not as exact science, but as hypotheses, and that no single abstraction like self-interest or scarcity could satisfy the requirements of so complex a subject-matter as economics." 4

3 Comorons, Notes of Analytic and Functional Economics (1926) 18.

4 Comarons, ANGLo-Amertcan Law aNd Economatcs (1926) 1. 
Nor can a single abstraction, that of positive physical force, be adequate for the comprehensive treatment of social phenomena in legal science. Among other factors which interact with that of scarcity, in the economic field, is the factor of positive physical force of the societal group, and these two factors, ${ }^{5}$ as Professor Commons has shown, are functionally so inseparably interrelated that the operation of neither can be understood without observing the operation of the other. By merely saying that we are examining the subject-matter as lawyers and not as economists or as sociologists, we cannot ehminate the other factors, including that of scarcity, which are complimentary with and are comphimented by positive physical force instrumentally employed by the societal group. Each of these factors are parts of the societal machine and together are wliat make it run. The machine's operation cannot be understood without understanding the operation of each of its parts, nor can the operation of any one of them be comprehended without understanding the operation of each of the others, and of all of the parts as they work together. Moreover, the same machine and the same parts or components form the subject-matter of the functional study of economics and of law, the field in which scarcity of resources is concerned, as Professor Commons has inade clear. ${ }^{6}$ At least, it may be said accurately that every element which enters into economic problems is involved in legal problems of corresponding subject-matter, and the converse is true with the possible exception that there may be some legal problems that do not involve economic considerations.

Another way of putting this is to say that every problem of a social group that concerns scarcity of resources and so has an economic pliase, also has a legal phase, i.e. a phase that concerns the working rules of the group. The abstraction or separate treatment of either phase can be only on the basis that the other phase is a settled matter and will remain constant so as to permit disposition of the problem in the case by dealing only with the phase which has been abstracted or separated. Thus the consideration of either phase inust always raise an inquiry as to whether the other one which is implicated in the problem has been adequately dealt with for the purpose or purposes with reference to which the problem at hand demands solution. What has been said or shall be said in this discussion, has been or shall pertain only to behavior within a social or societal group, unless otherwise indicated, i.e. to the behavior of individuals between each other in the group

${ }^{5}$ See works mentioned supra, note 2, especially Chapter III, in Commons, Legat Foundations of Caprtalism (1924) 47 and Conamons, Reasonable Value (1926).

6 Commons, Reasonable Value (1926); Commons, Notes on Analytic and Functional Economics (1926). 
including the collective behavior of all the individuals in the group, except one individual, toward that individual and his behavior toward them. As matter of mere physical behavior, the possible problems of a particular individual within the group will concern what he will be compelled by the group to do or not do, what he will be permitted to do or not to do without interference or penalization by the group, and what he can or cannot do with the assistance of the group. The conclusions drawn as to any of these questions will depend on observation as to the individual's physical capabilities and disabilities and prediction of the kind of behavior to be expected of the group. There are two phases involved: the mere physical phase pertaining to individual behavior and the phase pertaining to the behavior of the group, and it will take consideration of both in order to tell what will, may or can happen. The group behavior phase may, it seems, be called the legal phase in accordance with estabhished usage.

However, in relatively few instances and occasions do individuals act towards others in the group for the purpose of effecting physical results only. Most sueh action is directed at economic ends, the obtaining of results involving the satisfaction of wants as to which there are himitations because of scarcity of resources. As to such action it is plain that the individual's economic, in addition to his physical and his legal capabilities and disabilities determine what will happen. He will want to know whether from the standpoint of his physical ability it will be possible for him to do what he plans; whether the group will prevent, permit or assist him; whether the conditions, other than those pertaining to his physical abilities and disabilities and the anticipated behavior of the group toward him, pertaining to and affecting the scarcity of resources to satisfy human wants are such that he can or cannot accomplish the result desired by him. ${ }^{7}$ The different phases, which may be

7 "In dealing with law, ..., we are considering the conduct of societal agents and the rules expressing that uniformity with which they are expected to act. These rules are rules of law; but the rules that enable us to predict merely the action of natural forces or of individuals who are not societal agents are not rules of law. There is no supernatural or mystical distinction between physical relations and legal relations. Rules of physics and rules of law are alike in that they enable us to predict pbysical consequences and to regulate our actions accordingly. When the physical event that we are predicting is the conduct of a state agent, executive or judicial, acting for society, the rule that we are applying is called a rule of law; and with respect to the expected action of societal agents, our relations to our fellow men are commonly called legal (or jural) relations.

"It is not meant by the foregoing that this is the only possible usage of the terms in question. It is believed to be the actual usage, and that it is an advantage to abide by it. According to this usage, there is no law and there can be no legal relations of any sort where there is no organized society. The fact that is essential is the existence of societal force; and the question that is of supreme interest is as to when and how that force will be applied. What will the community of citizens 
called "the individual-physical," "the group-behavior (or legal)," "the scarcity (or economic)," thus involve factors that are complementary each to the others with respect to the purposive behavior of the individual, i.e. with respect to that anticipation or prediction into the future which will shape his immediate conduct. This, it is believed, is so obvious that it is likely to be lost sight of. In fact, it seems, it has usually been left out of contemplation in considering the operation of the working rules of a societal group. That is, the interplay or interaction between the individual-physical and the group-behavior factors has been observed, but the economic factor has been overlooked so as to leave out of consideration both the interplay or interaction between this third factor and each of the others and the residual sum total of these interactions. From the standpoint of the societal group in the making, changing, doing away with or retaining of working rules to cause individuals to behave as is desired this is important to the extent that the purposes of the group in the selection of working rules are economic, i.e. are aimed at the satisfaction of human wants from resources as to which there is scarcity.

On the basis that the societal group is organized and functions for the effectuation of the approved individual purposes of its members, it would seem then that the correlation between scarcity and group behavior would be found to exist to the extent or degree that economic purposes affect the behavior of the average individual in the group as compared with other kinds of purposes. And so, the societal group in considering action to cause the behavior of the individuals in the group to conform to a desired norm, will have to weigh the prospective composite inducing tendency of the economic factor in affecting their behavior in order to discover whether that economic factor is likely in itself to promote the desired behavior without the necessity of supplementing the economic factor or of independently stimulating the desired behavior by the employment or threat of group operated force other than or in addition to that by which the cohesion of the group is maintained and present working rules, which in a complementary manner keep the various economic elements or inducements that compose the economic factor functioning without diminution of effectiveness, are maimtained. If the economic factor is left to operate as it has been functioning in coordination with existing working rules supported or sanctioned by the collective physical force of the group in order that

cause their agents to do. It is this multitude of busy little fellow citizens who constitute "society" or "the state," and it is their cumulative strength that constitutes the personified giant whose arm may be so powerful to aid or to destroy. In law, the ultimate question is, what will this giant do?" Corbin, Jural Relations and their Classifications (1921) 30 YALE L. J. 226, 227. 
the desired end shall be promoted and effectuated, the decision thus to produce the stated end is as much a decision as to group behavior and the end, when attained, is as much the result of group behavior as if some positively violent coercive means were decided upon as necessary to be employed by the group, irrespective of economic inducements and to supplement or counteract them, and were put into operation. Moreover there is group constraint, i.e. the employment of group force as a factor, in the potential physical force by which the group gives backing to the existing working rules on the basis of which scarcity as an inducing factor of individual behavior is enabled to operate. Thus scarcity is employed as a group factor, when its employment by the group is purposive, as actually as is force through pohicemen, sheriffs and armies. Although it is not necessary that a proclamation be made that it has been decided to let the economic inducements continue to operate as they do under or in coordination with already existing formally announced working rules and no such proclamation is made, does not the decision adopt a working rule, a rule as to what the behavior of the group will be with respect to the matter concerned? And if a rule of law is a rule describing the predictable behavior of a societal group, does not the making of such a decision constitute the adoption of a rule of law $?^{8}$ Furthermore, whenever the societal group, whether as the result of much or bittle cogitation or deliberation or even of none, is content to let individual behavior of a certain kind go on with whatever effects it has and without interference with its occurrence and without modification or diversion of the course of its operation, is not the description of that fact as a phenomenon of which a prediction of group behavior may be made with uniformity, the statement of a rule of law, notwithstanding that the fact is understood without the making of a formal proclamation? Thus it would seem that a statement describing factual situations with respect to which the societal group will not intervene is as much a statement of a rule or rules of law as is one describing factual situations with respect to which the societal group will intervene. To refuse to describe a statement of a well-grounded prediction of nonintervention of the societal group as a statement of a rule of law (although a statement of predictable intervention is so described) is to simply make an arbitrary distinction in the use of the term "law," refusing to apply the term to any and all predictable group behavior and adopting it for one kind of behavior, i.e. positive, while rejecting it for another kind, i.e. negative. ${ }^{9}$ The justifiableness of such a distinction

8 Ibid.

${ }^{9}$ But any statement, including a statement descriptive of behavior can be put arbitrarily in either positive or negative form. See Goble, Affrmative and Negative Legal Relations (1922) 4 IrL. L. Q. 94, 96, n. 7. 
must rest upon convenience and utility. It is submitted that it is the more useful to apply the term "law" to all predictable behavior of the societal group and the term "legal" to any kind of societal group behavior, whether classified as positive or negative, because such employment calls attention to the complementary factors through which the societal group functions as a going concern and the means by the employment of which the group may effectuate its purposes.

The consequences of the complementary interaction of scarcity as a factor and group-operated physical force as a factor through the behavior of the group in employing them are not variable in importance merely by reason of variation in the proportioning of these factors which produce these consequences. Sometimes one complementary factor, sometimes the other is the himiting or decisive factor, i.e. the factor which determines the effect of the working rule adopted in the sense that it furnishes the final element that is needed to produce that effect. Thus, as has been indicated, sometimes it is considered necessary to adopt a new working rule, promulgated as one which will be supported by the physical force of the societal group, in which case such group force or the announcement of its prospective use may be said to be the limiting factor. At other times the composite operation of the economic inducements that influence the behavior between the individuals of the group is counted upon to produce the desired cousequences, conceived of either in terms of behavior or the results thereof, in working upon the base of and in coordination with already existing working rules, and is treated as the himiting factor.

The well-known case of $d r_{u} u n v$ Illinois $^{10}$ may be used to illustrate this. The decision upheld a statute which fixed the maximum charges that might be made for the storing and handling of grain in warehouses and elevators. By enacting the statute, the state promulgated a rule of law as one which would be enforced by the support of the societalgroup force of the state and that group force was the limiting factor adopted as the means of the effectuation of the rule. The end desired, an economic one, was the reduction of charges. On the other hand, had the legislature of Illinois decided not to regulate storage and handing charges in regard to warehouses and elevators the conclusion would have been to let a rule of law remain whereby the proprietors should be privileged to charge what they could under scarcity conditions and be left to acquire an economic monopolistic stranglehold whereby they might get what returns they wished. The factor of scarcity in that event would have been the limiting factor left in operation to produce a result which the legislature selected even though the selection may have been

10 (1876) 94 U. S. 113. 
made with more or less indifference of attitude. But what was involved was whether one rule or the other should be adopted and whether one kind of consequences or the other should be brought about, either a rule imposing a duty to restrict charges enforced by the potential employment of group force or a rule leaving to the proprietors a privilege to charge whatever they might get, the consequences of the rule being left to be accomplished through the ineans of scarcity as the limiting factor. Either of these two alternative decisions would have related to the same elements, viz: (a) scarcity conditions, (b) group behavior, active or passive, (c) consequences of the inter-action between the first two, upon behavior between individuals and upon scarcity as between individuals, and (d) purpose with reference to these consequences. The last two, consequences and purpose, are interconnected and can be treated under the term futurity. ${ }^{11}$ The functional study of scarcity relations between individuals in a societal group and the functional study of the behavior of a societal group with reference to human interests affected by scarcity have, then, the common elements of (a) scarcity, (b) group behavior, (c) futurity. They also have in common the elements of (a) physical capabilities and disabilities of individuals and (b) efficiency, the input-output.relation pertaining to the effectiveness of efforts. But as these elements do not vary according to variations between scarcity conditions and group behavior they need not be carried along in this discussion.

What is the place of custom with reference to the correlation of scarcity and group behavior? Is it not the result and manifestation of this correlation? ${ }^{12}$ It seems to be a product of the interrelation between the two factors of scarcity and group behavior which is so well established that its continuance with uniformity may be predicted. It is a

11 Comomons, Reasonable Varde (1926) 71.

12 ". . . as societies hecome organized, the politico-juridic function-which, with the economic function, meets the need of the group considered as such and forms the strictly social factor in history-gradually hreaks up into various institutions. 'Custom' is the undeveloped, or little developed, seed of all juridic development: morality and Law grow out of it. These institutions are distinguished from one another by the different nature of the sanctions by which they are maintained: an internal miperative in one case, coercion in the other. Law may be defined as the minimum of morality that is indispensable for life in society and is imposed by material sanctions." Henri Berr in Foreword to DECLAREUII, ROME THE LAWGIVER (1927). Berr seems to indicate the thought that law is a developed custom, when stabilized and supported by material sanctions, apparently including under material sanctions, not merely physical force brought to bear by the social group, or the sovereign, but that other material factor, the economic factor of scarcity. Such a synthesis of factors seems to be descriptively realistic. Moreover, developed custom seems to show the correlation between the factors of physical force and scarcity. It should be noted that both of these factors seem to be included by Berr under coercion, i.e. he seems to treat both as coercive. 
composite of scarcity, group behavior and futurity stabilized. As Professor Commons has said, it consists of "the repeated practices and transactions motivated by the inducements of individuals and the sanctions of groups, which hold out alternative expectations for the future."13 These repeated practices and the expectations of them, which are referred to by the term, custom, make the starting-point from which the adoption of new working rules or the discontinuance, modification or continuance of old working rules of the group require to be considered in order to comprehensively understand how most effectively to employ the behavior of the group to accomplish a group purpose. Custom is the inter-relation of scarcity inducements and group behavior sanctions in motion and any ehange made with respect to any of the latter may not only affect consequences by adding or diminishing its effect as a factor or as part of an intricate and delicate machine but by altering the coordination between each of the group behavior sanctions and each other, between each of the scarcity inducements and each other, and between each of the group behavior sanctions and each of the scarcity inducements. As with any intricate or delicate machine, a shight change that affects the coordination between parts may cause a great change in the functioning of the machine and in the product or consequences. The parts of the machine exist, their interrelation and coordination of some sort exists, the machine is in motion and functions in some way or other and with some effect or effects whether these facts are observed and considered or not. The failure to take account or make use of these phenomena does not stop the machine and keep it from operating. To isolate group behavior and disregard or fail to see that there is coordination between it and scarcity is to treat group behavior altogether inadequately with respect to its operation. This is the defect of analytic jurisprudence which thus leaves out of consideration the coordination, actual and possible, of group behavior with scarcity as complementary factors, either one of which, as the occasion may determine, may be employed as a limiting factor and also leaves out of consideration the scarcity, i.e. economic, consequences which are mainly what the individuals of the societal group resolve the group behavior effects into in the last analysis.

Functional jurisprudence takes account of this coordination and so does functional economics. The same means and the same ends are the subject-matter of both. Functional jurisprudence, in the economic field, takes various scarcity conditions and observes the effect of various kinds of group behavior with regard to scarcity consequences in reference to a purpose to produce certain scarcity consequences. Functional

13 Comorons, Notes on Analdtic and Functionat Econonatcs (1926) 58. 
economics takes various kinds of group behavior and observes the effect of various kinds of scarcity conditions with regard to scarcity consequences in reference to a purpose to produce certain scarcity consequences. All the differences are in emphasis and sequence of steps in the process of treatment. The constituents or elements dealt with are identical. The consequences considered and the purposes had in view are identical. Futurity is the key of their correlation. ${ }^{14}$ The ultimate functional question for both law and economics is: having a given hypothetical rule what will be its economic results? Functionally then, the science of Law, in the field of Economics, and the science of Economics are identical in content in that both deal with the correlation of group behavior and scarcity. Law may accurately be described as relating to expectations of societal group behavior or the behavior of societal agents to control individual behavior so as to determine economic consequences, or any other kind of consequences about which a societal group may have interest.

When there is a societal group holding together for the realization of the purposes of the individual members, the absence of any formal or express working rules does not mean that there is absence of group behavior, even though such behavior is that of passivity, and so it would not mean that "law" does not exist for the group. The tacit working rule is that the behavior of the individuals shall be stimulated to occur as influenced by the inducements employed between individuals. That working rule is "law" because it describes as a prediction that can be made uniformly and with reasonable assurance, what the societal group

14 "The meaning of any proposition can always be brought down to some particular consequence in our future experience, whether passive or active." JAMres, The Meaning of TrUTh (1909) 210.

"After all, the object of foresight of consequences is not to predict the future. It is to ascertain the meaning of present activities and to secure, as far as possible, a present activity with a unified meaning ... The problem of deliberation is not to calculate future happenings but to appraise present proposed actions." DEWEY, HUMAN NATURE AND CONDUCT (1922) 205.

A foreign writer, after quoting Mr. Justice Holmes' statement: "The prophecies of what courts will do in fact, and nothing more pretentious, are what I mean by the law" (Holares, Colrected Legal Papers (1921) 173) has gone on to say: "Law is, thus, a matter of prediction. It does not even consist of the rules already recognized and acted on in courts of justice, as Salmond would define it; it consists of the rules which the courts will most probably recognize or act on. This is no definition, to be sure. It is an apercu of wbat law actually is. It is of psychological, not of logical or mathematical essence. Psychologically, the law is a science of prediction par excellence. It concerns primarily our future interest; people do not study cases for pleasure, but generally with a view to anticipating what the courts will do when future cases arise. One constantly refers, it is true, to past cases as so many depositaries of the law, but in the last analysis this is done almost always with the intention of showing that there is sufficient ground for beheving that the courts vill act in such and such a way in the future." Wu, The Juristic Philosophy of Justice Holmes, (1923) 21 Micz. L. REv. 523, 530. 
behavioristically may be expected to do. If that expectation is of abstention from overt action, it is nevertheless an expectation as to a kind of societal group behavior. In such a case "the law" as to the behavior of any individual could be accurately described in the terms of "custom," i.e. uniform reptition of practices permitted by the societal group. An economist's study of the effect of scarcity inducements upon the behavior of individuals under the existing conditions would enable prediction of individual behavior and its economic consequences.

Now suppose that in the largest societal group, the state, there are no express or formal working rules so far as the behavior of individuals is concerned, the only rules being those respecting group organization, but that there are subordinate groups which in themselves are organized and in which there are repetitions of practices and the expectations of such repetitions so that these subordinate groups may be called going concerns. Are not the working rules, active or passive, adopted by these subordinate groups "law" for their members, since you can tell what the behavior of the subordinate groups toward their nembers will be and also can tell what the behavior of the chief societal group, the state, in respect thereto will be in allowing that behavior of the subordinate group to shape the behavior of the individuals in the subordinate group? If the subordinate group is permitted to exercise force upon its individual members and working rules for its employment have been adopted, "law" for the subordinate group is thereby determined. If it can hold together and successfully require certain conduct of its members by threat of expulsion froin the group, (which would deprive members of the economic advantages of membership in the organization and so operate upon them in this way by an economic sanction, as in the case of a labor union or guild) or, with this threat of expulsion in the background, impose fines and penalties, then the working rules backed by the economic sanction of the subordinate group, supported by the chief societal group, the state, imder its working rule of non-intervention, would be "law" as to both groups, subordinate and chief, in reference to the individuals affected. ${ }^{15}$ Or suppose

15 "All transactions occur as expectations of results to follow. These economic and juristic expectations may be distinguished as inducements and sanctions. Inducements are the motives of persuasion or coercion proceeding from individuals, but sanctions are commands requiring obedience and they proceed from groups of individuals, organized and unorganized. The principal one of these organized groups is the State. Thus each party to the transaction is inducing and being induced by the others, but each is limiting his inducements with knowledge and expectation of the sanctions that will be imposed by the group to which both are subordinate. There are other groups besides the State which impose these sanctions, the difference being that they do not impose the sanctions of sovereignty, but they do impose economic sanctions, as when a stock exchange or a labor union imposes rules upon its members enforced by the economic sanctions of fines, suspensions, expul- 
that a subordinate group is organized for non-economic purposes, as for example a church society, it would seem that working rules that might be passed which were based upon theological precepts would properly be described as "law" as to those within the society with respect both to the chief societal group, the state, and the subordinate group, the church society. These rules would really be comprised within a working rule of the state not to interfere with their operation. The threat of expulsion from the church society would operate as the limiting factor that determined the rule of the law.

sion, loss of customers or jobs. These rules of subordinate concerns are as truly juristic as those of the State, since they operate upon individuals through sanctions of group action rather than inducements of individual action, and thus they create expectations appropriately to be distinguished as rights, duties, liberties, and exposures." Commons, Anglo-Amorican Law and Economics (1926) 14. Cf. Corbin, Rights and Duties (1924) 33 Y ArEL.J.501, 502,n.4: "If there are several societal organizations of men, acting at times together and at times in competition, each with its own commands and sanctions, each with its own enforcing agents and procedure, then each will be creating a set of rights and duties within its chosen field. These last may at times directly conflict, one commanding 'thou shalt,' another 'thou shalt not.' Both are 'law', as long as one has not definitely overpowered the other. ... New groups of individuals are forming and organizing, competing for power, commanding and sanctioning. In so far as they can maintain themselves in the physical struggle, and in so far as their 'societal' action 'can be predicted, it may logically be said that they are creating 'rights' and 'duties.' Differences in degree are not negligible, however, and it may be inadvisable to dignify with the term 'law' or the term 'rights' the rules and sanctions of every association of lunatics or every criminal Mafia."

Where a subordinate group imposes rules enforceable by economic influence or coercion of that group with the permission of the chief societal group, i.e. the state, and under a rule of the latter not to intervene, there seems to be no difficulty about treating these rules of the subordinate group as also being working rules of the chief group and hence as law for the latter group enforceahle effectively through the economic coercion of the subordinate group smce the behavior of the chief group is to refrain from exerting its collective coercion or pressure in order to allow the economic coercion or influence of the subordinate group to take effect. The means of the chief societal group in giving sanctions to enforce the working rule of the subordinate group which the chief group adopts as its own is the economic coercion apphed by the subordinate group. The present writer does not feel that there is any sacred necessity for using the term "sanction" solely in the sense of some specific application of positive group coercion being impending to directly compel compliance or to directly penalize non-compliance with a working rule of a societal group before you can call such a working rule law for that group. For example, it is not necessary that an army or a sheriff be held in readiness to be sent out to compel compliance or penalize non-compliance. In this sense there should not bave to be a sanction. It should be necessary only that group behavior of some kind could be counted on. So here it would seem that the economic coercion applicable within the subordinate group through the chief societal group's refraining from interfering or intervening should be regarded as sufficient to make the working rule of the suhordinate group also a working rule for the chief group and hence law for both groups. If it is insisted upon that the term "sanction" be employable, it seems plausible that the subordinate group's predictable application of economic coercion should not only be sufficient to constitute a sanction for its working rule but also to furnish a sanction for that working rule as a working rule, and so a "law", of the chief societal group as well. 
The importance of scarcity as a complementary factor and in many instances as the limiting factor in correlation with the group behavior factor should be fully realized and borne in mind. It should not be overlooked that in an organized society, i.e. societal group, the scarcity factor may be fully as effective in influencing conduct as the physical force of the societal group by itself is or could be and so when the scarcity factor is left to operate to its consequences, the consequences are "legal" or should so be treated no less than where group physical force has been or is employed as a predominating influence.

\footnotetext{
"Under circumstances of great scarcity, where the opportunities for livelihood are limited, the economic sanctions may be so powerful as to be indistinguishable from the physical sanctions. This was evidently the case with primitive village commumities, where without an independent judiciary for the trial of disputes, the physical sanctions were not separated from the scarcity sanction and each was merged in the intolerance of undisputed moral and religious traditions. The scarcity of resources was so pressing as to compel everyone to conform to the customs or perish. It is only in modern periods of abundance that the economic sanctions seem to retire, and the physical sanctions of sovereignty seem to be the only sanctions of 'law'. The analytic jurisprudence of Austin, which eliminated all economic sanctions under the generalization of positive morality, could not arise in periods of scarcity-it was an outcome of the wealth of England after the Eighteenth Century."16
}

The term "sanction" has been employed traditionally to refer to group physical force potentially available to directly coerce obedience or coercively penalize disobedierce to a rule of the group as a command and it has been orthodox to say that no rule is a rule of "law" unless it is enforceable by a "sanction" in this sense. But whether the term "sanction" is used or not, it would seem that when the societal group adopts a working rule of physical non-intervention in order to afford scarcity factors the opportunity to operate fully to produce a desired and aimed at consequence, it would be merely arbitrary to say that the working rule is not "legal" just because direct physical coercion by the group is abstained from where conceivably it wonld not be as effective to accomplish the group purpose and as a matter of societal engineering, is displaced as a group instrument. The factor of potential collective group force is present and the holding of it in check results in different consequences or at least consequences produced in a different way than those which would have been brought about had the group force been put into positive operation and not withheld. Moreover it would seem that there is not only a withholding of group force from overt interaction with the scarcity factor but there is a holding of the group as a functioning going concern so that it continues to function

16 Comarons, Notes on ANarytic and Functionar Economics (1926) 36. 
without repression or diminution or modification of the action or interaction of the elements and factors that are already in operation. May it not then be said without misdescription of what really happens, that there is a group behavior sanction as a holding sanction, as a withholding sanction, or as a sanction of non-intervention? Nor does it seem inaccurate to say that there is an economic sanction with respect to any working rule adopted by the societal group with respect to which individual behavior is made to conform uniformly to a certain desired pattern by the operation of scarcity as a limiting factor, purposively given full scope to nake itself effective through being left free by the societal group's holding its collective force in restraint with reference to the enforcement of the working rule. Says Professor Commons:

"It is sometimes objected to this 'functional' view of jurisprudence that it seems to present sovereignty as all-pervading in its activity, a kind of 'big stick' always in use, whereas it actually is not used in far the great majority of transactions. Indeed, much more extensive are the economic, ethical, or other societal mducements in determining human behavior. This objection, we consider, misses the point upon which all human inducements operate-the expectations of the future. The all-pervasiveness of force does not signify that the physical force of sovereignty is actually employed in all transactions - that would be either anarchy or slaveryit does not signify that force has been brought within certain rules of procedure, upon confidence in which individuals and groups may go ahead without fear of violence if they behave themselves in their social and economic transactions. The test of this all-pervasiveness is simple enough-let the state with its courts and sheriffs and similar officers disappear-then of course all economic, social and ethical inducements will be different. The all-pervasiveness of sovereignty is simply the human function of futurity guiding the transactions of the present upon the expectations of the shape which physical force will take in the future." 17

The concept of law should conform to a realistic description of societal group behavior, which like individual behavior, nuay consist not only of unlimited positive exertion or notion with respect to the accomplishment of a particular purpose but also of entire abstention or avoidance of any positive exertion or notion to alter or prevent an anticipated consequence or of hinited positive exertion or motion, quantitatively made up of the employment of positive exertion or motion up to a certain limit with forbearance from positive exertion or notion beyond that limit, on the farther side of which there is the negative behavior of avoidance or abstention. ${ }^{18}$ In any given situation where one kind of consequence will be produced by positive action

17 Ibid. 14.

18 Comomons, Legaz Foundations of Capitalism (1924) 77: “. . Every transaction is a double-edged performance, avoidance, forbearance. Each party to the transaction acts, at one and the same moment in three dimensions. His performance is his power put forth in acting. His forbearance is the limit which he or a superior authority places on the degree of power im acting. His avoidance is his choice of that 
another kind of consequence will be produced by avoidance of such positive action; and if a quantitative limit is placed upon the amount of positive action that is taken, the placing of that quantitative limit and thereby fixing the proportion between the positive behavior of action and the negative beliavior of avoidance, may, and under many situations will, determine the kind of consequence that is produced.19 What happens will be no less consequential from group beliavior, whatever its type or kind or the classification adopted to designate that beliavior as of one or of another type or kind, e.g. positive, negative. The method of employment of the physical force of the societal group is by placing limits on its application and at the same time on its nonapplication, thus proportioning the two so as to get the effect desired. The societal group functions by determining when and when not to employ it positively and how, i.e. to what extent, in particular instances. A limited employment of societal group force which produces a result desired in one case should not be considered less important than the unlimited employment of it in another case to produce a desired result; nor should the complete withholding or avoidance of its application in another case be considered less important if thereby the desired result may be produced. And besides it may be ventured that in many instances the quantitative determination of where to place the limit: upon the positive employment of collective group force will affect the result to as great an extent as the qualitative determination of whether or not to apply it at all.

Where a subordinate group or going concern enforces a working rule by a so-called economic sanction permitted to operate by reason of non-intervention of the chief societal group or going concern, the working rule of the subordinate group should be treated as a rule of law as to that group and also as a rule of law of the chief societal group in the field of the subordinate group. And it seems hardly less reasonable that a working rule of a societal group, within which there is no subordinate group, to the effect that the group will refrain from interposing its collective physical force with respect to a particular matter and as to that matter will allow full operation to scarcity inducements or ethical or other inducements as between individuals should be treated as a rule of law. Moreover, a relation which inay be described by saying that in a particular factual situation between two individuals the one

performance instead of any alternative performance. Every act of an individual is, at one and the same point of time, a performance, a forbearance, an avoidance. While the person is not doing an alternative thing (avoidance), he is doing something else (performance), and the thing which he is doing is usually something less (forbearance) than the total degree of power he might exert."

19 "At the same time, each performance of physical, economic or moral power is an avoidance of any and all alternative performance." Ibid. 79. 
may not successfully invoke the intervention of the societal group should be called a legal relation none-the-less than a relation which may be described by saying that in a particular factual situation between two individuals the one may successfully invoke the intervention of the societal group. That is, the term "legal relation" should be used to describe predictions of any kind of societal group behavior with reference to any factual situation between two individuals. This is convenient and takes into consideration that societal group purposes or ends are accomplished or reached not merely through the positive employment of the collective physical force of the societal group as the limiting factor but also, at times, through the operation of the scarcity factor, or possibly even some other factor, as the limiting factor without the positive employment of societal group force. Provided a prediction may be made with umiformity, i.e. with probability and concerns societal group behavior with reference to a relation between individuals, the statement of the prediction should be treated as a statement of law and of one or more legal relations whether active or passive bchavior of the societal group is predicted..$^{20}$ The individuals involved would be as much interested in the prediction whether it expressed an expectation of societal intervention or of societal non-intervention and could be affected fully as much in either case with respect to their individual future behavior. ${ }^{21}$

It should be noted that the statement of an economic relation includes a statement of the legal relation between two individuals and also a statement of expectations with respect to scarcity of resources. Legal relations are made of the behavior of the societal group toward individuals, usually through societal agents. The description of legal relations is the description of that behavior. This is the content of the science of analytical jurisprudence. But the science of functional jurisprudence also includes the study of what these legal relations, i.e. societal group behavior, should be in order to accomplish the social ends of the societal group. The behavioristic science of economics, dealing with the scarcity of liuman resources, has to be studied with reference to societal group behavior to determine how by employing the group

20 "The common law consists of ... uniformity and consistency in judicial and administrative conduct. Its rules and principles are statements in words of this uniformity and consistency. In this fundamental aspect the common law is not different from the laws that we think that we have discovered in physics or in chemistry. A law is a statement of uniformity in the past sequence of events, based upon the recorded observation of those events, by the help of which we believe we are able to predict the future course of events. This is true, whether the uniformities that have been observed are uniformities in judicial action or uniformities in the conduct of atoms or planets or suns." Corbin, The Restatement of the Common Law by the American Law Institute (1929) 15 IowA L. Rev. 19, 26. See also supra note 7.

21 See Goble, Affirmative and Negative Legal Relations (1922) 4 Ir工. L. Q. 94. 
behavior factor, actively or passively, together with the scarcity factor, each factor being complementary to the other and sometimes one and sometimes the other being available as the limiting factor, the ends desired may be brought about. Those ends themselves very often are economic ends, i.e. consequences with reference to scarcity. Law, as an instrument of group ends, involves economics as to the content of its ends and as a factor of control in their accomplishment. ${ }^{22}$

Raymond J. Heilman.

\section{San Francisco, CaLIforata.}

22 As Professor Coinmons has explained, the correlation of the behavior of the societal group with the behavior of the individual with respect to scarcity of resources when analyzed more minutely so as to show the operation of group behavior infuences, may he observed in the economic transaction, the simplest functional unit in which these factors operate. In the transaction the economic inducements operate as between two sets of competitors, with each competitor in each set endeavoring to employ his economic power in rivalry with another's employment of his econounic power to obtain an economic object, as to which there is an opportunity for both. In the common concrete market example there are competitive prospective buyers on one side and competitive prospective sellers on the other. A thing to be sold is the object for which the buyers compete. Another thing to be exchanged for the thing sold as the price for the latter, this thing to be exchanged as the price usually being money, is the object for which the sellers compete. The bargaining that goes on in the transaction, will on each side resolve itself into a contest between the highest and the next highest bidder and the bidder with the greater economic power as between the two will be able to prevail. The price at which the sale is made will fall between the best opportunity for the actual seller and the best opportunity for the actual buyer, i.e. between the highest price the actual seller cain get from the competing buyers and the lowest price the actual buyer can get the competing sellers down to. Any of the individuals concerned will be affected with respect to these economic dimensions of (1) economic opportunity, (2) economic power in a situation involving (3) economic competition and so to realize fullest opportunity, greatest power, least competition from a rival or rivals would be interested in the employment of group behavior to regulate the individual behavior of a rival or rivals. He would be interested in having limits placed upon his rival's behavior with regard to these three phases. The limits that exist and are maintained by the societal group or that are fixed and enforced through the means of societal behayior that are adopted by the group are to be described in terms of legal relations. We thus have the correlation of legal relations with economic relations through the analysis of the bargaining transaction. If we assume the organization of a societal group which regulates the behavior of the four bargaining parties, we may treat the societal group as a fifth party concerned about the behavior of the bargaining parties or treat a fifth person as a societal agent representing the group in the role of an arbiter or judge or ruler.

"A transaction, then, involving a minimum of five persons and not an isolated individual nor even two individuals, is the ultimate unit of economis, ethics and law. It is the ultimate but complex relationship, the social electrolysis, that makes possible the choice of opportunities, the exercise of power and the association of men into families, clans, nations, business, unions and other going concerns. The social unit is not an individual seeking his own pleasure: it is five individuals doing something to each other within the limits of working rules laid down by those who determine how disputes shall be decided." Commons, Legat Foundations of Capitalisar (1924) 68. 